\title{
Recipient Selection to Support The Success Rate of Frozen- Thawed Belgian Blue Embryo Transfer
}

\author{
Weni Kurniati ${ }^{1,2}$, Muhammad Agil ${ }^{3 *}$, Bambang Purwantara ${ }^{3}$, and Muhammad Imron $^{4}$ \\ ${ }^{1}$ Embryo Livestock Centre Cipelang-Bogor, Indonesia \\ ${ }^{2}$ Reproductive Biology Study Program, Graduate School, Faculty of Veterinary Medicine, IPB University, Bogor, Indonesia. \\ ${ }^{3}$ Division of Reproduction and Obstetrics, Department of Veterinary Clinic, Reproduction and Pathology, Faculty of Veterinary \\ Medicine, IPB University, Bogor, Indonesia. \\ ${ }^{4}$ Directorate of Nurseries and Animal Production of the Ministry of Agriculture, Republic of Indonesia
}

\begin{abstract}
Frozen-thawed Belgian Blue (BB) Embryo transfer (TE) is an effort of fulfilling meat demand in Indonesia. This research aimed at observing the correlation between estrus expressions of standing heat and the correlation of CL characteristics on the success rate of frozen-thawed BB embryo transfer. The study was conducted on 55 recipient cattle with 62 times of TE application, which were categorized into three groups, namely FTET estrus synchronization $(n=14), 24$-hour natural estrus detection $(n=30)$ and twice-a-day natural estrus detection $(n=18)$. The implemented synchronization was the combination of estradiol-progesterone and hCG with the modification of 24-hour estrus detection between day-9 and 10 . The second method was a natural estrus detection, which was conducted four times for 30 minutes, and the third method was twice-aday estrus detection for 90 minutes. The CL characteristics were observed using ultrasonography (USG) in the TE application day. Pregnancy per ET (P/ET) was determined by ultrasonography on d-20, 30, and 50. This research revealed that expressions of standing heat increased P/ET $(\mathrm{P}<0.05)$. The pregnancy loss rate was lower of the recipient which showed the estrus expression of standing heat (18.18\%) compared to recipients did not show standing heat $(40 \%)$. Based on the estrus detection method, there was no significant difference between the FTET modification method and the percentage of pregnancy $(p>0.05)$. The CL characteristics showed there was no correlation between CL diameter with the pregnancy success rate of TE $(\mathrm{p}>0.05)$.
\end{abstract}

Keywords: estrus detection, CL characteristic, frozen-thawed Belgian Blue embryo transfer, standing heat.

\section{Introduction}

The demand for beef in Indonesia continuously increases along with population growth. Meanwhile, the supply of local cow meat currently on average only fulfills $65.24 \%$ of the national need [1]. Various efforts are conducted to overcome that problem, one of them is by implementing reproduction technology to increase genetic performance related to the productivity increase, which is the utilization of Embryo transfer (TE) technology [2].

Embryo transfer (TE) is reproduction biotechnology which has the advantage of being able to accelerate the increase in livestock's genetic quality and obtaining highquality genetic cows with a significant number in a fast time [3]. Another advantage is that the distribution of frozen-thawed embryo is more efficient compared to livestock distribution, therefore the acceleration of livestock quality improvement can be achieved [2]. The accelerations are conducted through TE using a frozenthawed Belgian Blue (BB) cow. Belgian Blue is known to have high efficiency with large muscle mass and rapid growth $[4,5]$ so that it is expected to help food self sufficiency achieved.
Application of TE in Indonesia began in the 1980s, however, until now the success rates of TE varied and the impact is relatively small for the development and the increase in livestock production [2]. One of the causes of that is the difficulties of finding recipients which are appropriate of transfer in the field [6], in which it depends on the accuracy of estrus detection [7] and the quality of corpus luteum (CL) during transfer [3].

Estrus detection is an essential aspect of the success of TE since it determines TE application time [8]. Standing heat expression is the best predictor for ovulation time and has a positive correlation with estradiol concentration [9, 10]. [11] assert that estrus expression of standing heat on recipient cows significantly affects the success of TE. The occurring problem is the difficulties in determining estrus expressions accurately and efficiently [12]. This encourages numerous studies which develop estrus detection methods, among them are manual observation 4 times a day [10] using instrument such as tail paint and estrus detector [12] or synchronization the time of ovulation use estradiol (E2), progesterone (P4), and PGF2 $\alpha$ to synchronize ovarian function and time

* Corresponding author: rhinogil@googlemail.com 
ovulation to allow fixed Time TE /FTET [7]. The occurring problem in Indonesia is that estrus detection is generally only performed twice-a-day and estrus criteria assessment is not yet set as one of the requirements of transfer-appropriate recipient selection.

Another aspect besides precise estrus detection which becomes important is the quality of CL on TE application day [6]. This is in line with the statement by Spell [3] who states that the size and character of CL during transfer cannot increase the success rate of TE. Meanwhile, [13] who researched beef cattle states that the success rate of pregnancy is influenced by CL size. Many factors mentioned above became the background of this research which was conducting recipient selection with various estrus detection methods to identify the correlation between estrus expression of standing heat as well as CL characteristic in the success rate of frozenthawed BB embryo transfer.

\section{Materials and Methods}

This research was conducted at the Livestock Embryo Center (BET) Cipelang, Bogor. This study was held from January to December 2018. The recipients used in this study were 55 female Friesian Holstein cows with the ages ranged between \pm 4-7 years old, healthy, have a normal estrus cycle and minimum has given birth once. The body condition scores (BCS) were between 2.75 to 3 and not pregnant. The livestock was maintained in a freestall housing system, forage-fed and concentrate.

\subsection{Detection of Estrus}

Estrus observation was conducted visually by observing the estrus expression shown by recipients which were determined by estrus clinical expressions; the discharge of vaginal mucus, red-colored vulva, swelling, smelling and sniffing mount another female, standing heat for $\geq 5$ seconds.

Table 1. The assessment of estrus expressions

\begin{tabular}{ll}
\hline Estrus expressions & Observable Estrus expressions \\
\hline $\begin{array}{l}\text { Without the } \\
\text { expression of } \\
\text { standing heat }\end{array}$ & $\begin{array}{l}\text { The discharge of vaginal mucus, } \\
\text { smelling and sniffing another female } \\
\text { vulva, mounting another female }\end{array}$ \\
Standing heat & Standing heat for $\geq 5$ seconds
\end{tabular}

\subsection{Animals and Treatment}

Transfer embryo applications were conducted 62 times on 55 cow recipients; which the 7 cows were not pregnant on the first application, and then another transfer was performed on the next cycle. The first group was a natural estrus group consisted of 48 cows, and the second group was a synchronization group (FTET) consisted of 14 cows. The natural estrus group was categorized into two subgroups, namely twice-a-day natural estrus (30 cows) and 24-hour observation (18 cows).
The implemented embryo transfer method was direct. The used embryo was a 7-day-old frozen-thawed BB embryo. The qualification of the used embryo was embryo with good or excellent quality, referring to the embryo assessment criteria released by IETS (International Embryo Transfer Society).

The identification and measurement of $\mathrm{CL}$ were conducted directly using USG (Draminski 4Vet Portable Ultrasound $®$ ) had straight rectal transducer with doppler B-Mode and a frequency of 7.5 Mhz. The ovary was scanned several times with latero-medial and dorsoventral positions to obtain the longest CL diameter, and The CL cavity was measured as a correction factor. Embryo transfer was conducted in ipsilateral with CL.

\subsection{4-hour Natural Estrus Detection}

The natural estrus method was conducted by estrus detection on recipients, and day- 0 was calculated from the emergence of estrus expressions. The detection was performed 24 hours four times in 30 minutes of each observation (04.00, 10.00 AM and 04.00, 10.00 PM). On day- 0 , the observation was conducted using USG. Transfer embryo application on day-7 after estrus expressions was observable.

\subsection{Twice-a-day Natural Estrus Detection}

The estrus detection method used the same method as conducted for 24 hours of detection. Except, the detections were conducted twice a day for 1.5 hours of each, which were at 06.30-08.00 a.m. and afternoon at 12.00-01.30 p.m.

\subsection{Estrus Synchronization}

The synchronization method used the protocol modification of Fixed Time Embryo Transfer (FTET) (Bo et al. 2002) with the additional estrus detection. The FTET protocol was conducted using the progesterone implant combination of intravaginal progesterone (P4), estradiol benzoate (EB), human chorionic gonadotrophin (hCG) and prostaglandin (PGF2a). The intravaginal progesterone $\left(\mathrm{Cu}-\mathrm{Mate}^{\circledR}\right)$ was inserted on day-0, $2 \mathrm{mg}$ Estradiol Benzoate (EB) $\left(\right.$ Merck $\left.^{\circledR}\right)$ and $50 \mathrm{mg}$ P4 $\left(\right.$ Potahormon $^{\circledR}$ ) was injected in intra-muscular (IM) at the same day. On the day-5, $5 \mathrm{ml}$ (25 mg dinoprost tromethamine) PGF2a (Lutalyse ${ }^{\circledR}$ ) was injected. CueMate ${ }^{\circledR}$ implant was removed on day-8, thereafter on day9 was injected with $1 \mathrm{mg}$ EB and $1.500 \mathrm{IU}$ hCG $\left(\right.$ Chorulon $^{\circledR}$ ) intra-muscular (IM). TE application was conducted on the day-17.

\subsection{Pregnancy Success and Pregnancy Loss}

The pregnancy examination was conducted using USG. The USG technique used was real times (B mode), using transrectal Doppler USG (Draminski $4 \mathrm{Vet}^{\circledR}$ ), with a frequency of $7.5 \mathrm{MHz}$ transducers linear rectal. Pregnancy success (P/ET) was calculated using the pregnant cows at the pregnancy diagnosis at day-20, 30 
and 50 from the total number of the cow that ovulated (CL present on day-7). Pregnancy loss was calculated by dividing the number of cows that lost their pregnancy after day-20 by the number of pregnant cows at pregnancy diagnosis on day-20.

\subsection{Statistical analysis}

The obtained data to determine the correlation of CL characteristics with the success rate of TE pregnancy were analyzed using Pearson simple correlation test. The correlation between estrus detection and estrus expressions of standing heat on TE pregnancy success rate was analyzed using Chi-square with $\alpha=0.05$.

\section{Results and Discussion}

The present study revealed that estrus detection using FTET modification method and 24-hour natural estrus detection increased the number of recipients with estrus expressions of standing heat higher which were $42.86 \%$ and $50 \%$ respectively compared to twice-a-day detection which was $22.2 \%$. The pregnancy rate on standing heat recipients with FTET and 24-hour estrus detection methods was $83.3 \%$ and $33.3 \%$, respectively. While twice-a-day estrus detection was $25 \%$ only (Table 2 ).

Table 2 Effect of various estrus detection methods on the percentage of TE success rate

\begin{tabular}{|c|c|c|c|}
\hline \multirow[b]{2}{*}{ Parameter } & \multicolumn{3}{|c|}{ Method } \\
\hline & FTET & $\begin{array}{c}\text { 24-hour } \\
\text { natural } \\
\text { estrus }\end{array}$ & $\begin{array}{l}\text { Twice-a-day } \\
\text { natural estrus }\end{array}$ \\
\hline $\begin{array}{ll}\text { Standing heat } \\
\text { recipient }\end{array}$ & $\begin{array}{c}6 / 14 \\
(42.86)\end{array}$ & $\begin{array}{c}15 / 30 \\
(50)\end{array}$ & $\begin{array}{l}4 / 18 \\
(22.2)\end{array}$ \\
\hline $\begin{array}{l}\text { Standing heat } \\
\text { recipient's } \\
\text { pregnancy }\end{array}$ & $\begin{array}{c}5 / 6 \\
(83.3)\end{array}$ & $\begin{array}{l}5 / 15 \\
(33.3)\end{array}$ & $\begin{array}{l}1 / 4 \\
(25)\end{array}$ \\
\hline $\begin{array}{l}\text { Non-standing } \\
\text { heat recipient's } \\
\text { pregnancy }\end{array}$ & $\begin{array}{l}0 / 8 \\
(0)\end{array}$ & $\begin{array}{l}3 / 15 \\
(20)\end{array}$ & $\begin{array}{c}2 / 14 \\
(14.28)\end{array}$ \\
\hline
\end{tabular}

The estrus detection to determine the day- 0 on TE application is an essential aspect in determining the success rate of TE [14]. According to [10], twice-a-day estrus detection only has $19 \%$ of the possibility to observe standing heat, and the percentage would increase by $30 \%$ if the estrus detections were performed three times a day for 30 minutes. With a higher accuracy number, the pregnancy rate was also expected to be higher [15].

The fixed time embryo transfer/FTET synchronization method was used to increase the efficiency in livestock management without estrus detection [8]. In the present study, FTET was modified conducted by additional estrus detection. The success rate of pregnancy with the FTET modification method had a significant difference $(\mathrm{p}<0.05)$ between recipients which showed estrus expressions of standing heat and non- standing heat. The pregnancy rate of recipients which showed estrus expressions of standing heat at the pregnancy period of 30 and 50 days was $66.6 \%$. Meanwhile, the recipients who did not show estrus expressions of standing heat had a pregnancy rate of $0 \%$ (Table 3).

The expression of standing heat shown a significant effect on the TE success rate of recipients $(p<0.05)$. The recipients who showed estrus expression of standing heat had a pregnancy rate of 44\%; while the cows which showed estrus expression without standing heat had a pregnancy rate of $13.51 \%$. In the present study, estrus expressions of standing heat did not have a significant pregnancy loss compared to non-standing heat ( $\mathrm{p}>0.05$ ). However, based on the percentage of non-standing heat recipients had a higher rate of pregnancy loss (40\%) compared to the recipients which showed standing heat (18.18\%) (Table 3).

Table 3 The correlation of TE success rate and estrus expression

\begin{tabular}{|c|c|c|}
\hline \multirow[b]{2}{*}{ Pregnancy (\%) } & \multicolumn{2}{|c|}{ Estrus expression } \\
\hline & Standing Heat & $\begin{array}{l}\text { Non-Standing } \\
\text { Heat }\end{array}$ \\
\hline \multicolumn{3}{|l|}{ FTET } \\
\hline $\mathrm{d}-20$ & $5 / 6(83.3)^{\mathrm{a}}$ & $0 / 8(0)^{\mathrm{b}}$ \\
\hline$d-30$ & $4 / 6(66.6)^{\mathrm{a}}$ & $0 / 8(0)^{b}$ \\
\hline$d-50$ & $4 / 6(66.6)^{\mathrm{a}}$ & $0 / 8(0)^{\mathrm{b}}$ \\
\hline \multicolumn{3}{|l|}{ Natural estrus } \\
\hline$d-20$ & $6 / 19$ (31.57) & $5 / 29(17.24)$ \\
\hline$d-30$ & $5 / 19(26.31)$ & 4/29 (13.79) \\
\hline$d-50$ & $5 / 19(26.31)$ & $3 / 29(10.34)$ \\
\hline All Method & $11 / 25(44)^{\mathrm{a}}$ & $5 / 37(13.51)^{\mathrm{b}}$ \\
\hline Pregnancy Loss & 2/11 (18.18) & $2 / 5(40)$ \\
\hline
\end{tabular}

The combination of estradiol and progesterone will suppress antral follicle development. This mechanism affects systemically on minimizing estrogen secretion and the inhibition of follicle growth so that it affected the decrease in FSH hormone production. Once estradiol is metabolized, FSH concentration will arise in circulation and followed by follicle wave of $4.1 \pm 0.1$ days after the treatment [16], the ovulation can occur on the day-10 [17]. The synchronization method with the combination of estradiol-progesterone on TE application is reported to be able to increase the number of recipients between $75-80 \%$ $[8,17]$. The use of $1 \mathrm{mg}$ EB on day-9 in this method functioned to increase LH concentration significantly and cause ovulation [18]. According to [19], the administration of estradiol $1 \mathrm{mg}$ exogenously and hCG exogenously has been able to increase LH concentration and cause ovulation.

The results present study were in line with the report by [11] as well as [20] that state that estrus expression has a significant correlation with the success rate of TE. [11] state that recipients who showed estrus expression have the success rate of pregnancy 60 days higher $(37.5 \%)$ than the cows which did not show $(25.1 \%)$.

This result for pregnancy loss rate is in line with the research by Bó and [20] that standing heat estrus 
recipients have a lower rate of pregnancy loss (20.5\%) compared to no standing heat estrus recipient $(66.7 \%)$. The incidence rate of TE application pregnancy loss in the second week was 26-38\%, depends on the embryo type and recipients' status [21]. However,[22] mentioned pregnancy loss usually occurs in the third week of pregnancy. Therefore in this study, a pregnancy lost was observe until day-50 to cover also the embryonic death before the fetal phase.

Estrus expression can become an appropriate sign to be used as a reference to conduct TE application [20], ) and correlated with uterus environmental change on the first 7 days of embryo development [11, 20]. Uterus environment to maintain the first stage of pregnancy after TE is mainly influenced by estradiol and progesterone concentrations [23, 24]. Estradiol concentration on day-0 and progesterone serum on day-7 significantly influenced TE pregnancy on day-27. Estrogen concentration has an important role in increasing the number of progesterone receptors on the endometrium [25]. [26] reported that estradiol concentration during the preovulatory importance period for survival of embryo transfer day-7 and pregnancy establishment. Based on [26], their research results showed the pregnancy success rate based on interferon-stimulated gene (ISG) concentration on the pregnancy periods of 17-21 days were not significantly different between cows estradiol-treated and cows without receiving exogenous estradiol. However, the pregnancy-specific protein B (PSPB) concentration was measured on day 24 showed a significant difference for estradiol-treated cows compared to untreated cows. PSPB concentration indicated there was a specific signal [27] which was produced by a trophoblastic cell on the day-15 of the pregnancy period and circulated through mother circulation during placental attachment [28]. Therefore, the result above showed the cows which did not have sufficient estradiol concentration during proestrus/estrus, the embryo was able to deliver maternal recognition signal but the placental attachment was not become very intimate to maintain the pregnancy [26]. Standing heat estrus expression describes the sufficient estradiol concentration during estrus/proestrus [15] becomes an indication that all reproduction tissues are ready to receive an embryo [29].

The result in the present study revealed that CL size and CL cavity did not have any correlation with TE success rate $(\mathrm{P}>0.05)$. The average $\mathrm{CL}(\mathrm{mm})$ diameter in this research for the pregnant recipients was $22.3 \pm 4.1$ and for non-pregnant was $20.7 \pm 3.4$. The results of this study were in line with the study reported by [3], however, they were different from the report by [8] which stated that TE success rate correlates with the corpus luteum diameter. Furthermore, [30] report the average cavity size of CL which is similar to this study was about $8 \mathrm{~mm}$.

Corpus luteum functions to synthesize progesterone so that the mother can maintain the pregnancy [31]. Progesterone has a role in stimulating the uterus to produce nutrition secretion, which has a role in embryo development. Progesterone concentration after ovulation has a significant correlation with embryo life survival [32]. Although the result found there was no correlation between the size of CL and the success rate of TE, the present of CL was critical and important to maintain the success of pregnancy.

\section{Conclusion}

Estrus expressions of standing heat have a significant effect on the success rate of frozen-thawed BB embryo transfer and CL characteristics did not have any correlation on the success rate of frozen-thawed BB embryo transfer.

\section{Acknowledgment}

The authors acknowledge the Agricultural Extension and Professionals Development Agency, Indonesian Ministry of Agriculture for providing the funding and Livestock Embryo Centre Cipelang-Bogor.

\section{References}

1. [Ditjen $\mathrm{PKH}]$ Direktorat Jenderal Peternakan dan Kesehatan Hewan: Petunjuk pelaksanaan Upsus Siwab 2017. Jakarta (ID). Ditjen PKH Kementerian Pertanian. 2017.

2. Adriani, Rosadi B, Depsion: The Quantity and Quality of Brahman Cross Cattle Embryo After Injected FSH and PMSG. Anim Prod. 2009; 11 (2):96-102.

3. Spell AR, Beal WE, Corah LR, et al.: Evaluating recipient and embryo factors that effect pregnancy rates of embryo transfer in beef cattle. Theriogenology. 2001; 56: 287-297.

4. Coopman F. Morphometric assessments in the double muscled Belgian Blue beef breed. Review. Gent Universiteit. 2008.

5. Leroy PH, Famir F, Alvart A, et al.: The use Belgian Breeds in the improvement of animal production in the tropic. International conference on agricultural development in the context of international integration. Vietnam National University of Agriculture. 2015; 3-15.

6. Lestari DJ, Ismudiono I, Sardjito T, et al.: The success of embryo transfer in dairy cattle recipients using beef cattle embryos. Lucrari Stiintife-Seria Zootehnie. 2016; 45:203-208.

7. Bó GA, Peres, Cutaia, et al:: Treatments for the synchronization of Bóvine recipients for fixed-time embryo transfer and improvement of pregnancy rates. Reprod Fertil Dev. 2012; 24:272-277.

8. Bó GA, Baruselli PS, Moreno D, et al.: The control of follicular wave development for self-appointed embryo transfer programs in cattle. Theriogenology. 2002; 7:5372.

9. Diskin MG, Sreenan JM: Expression and detection of oestrus in cattle. Reprod. Nutr. Dev. 2000; 40:481-491.

10. Roelofs JB, Van Edenburg FJCM, Soede NM, et al.: Various behavioral signs of estrus and their relationship with time of ovulation in dairy cattle. Theriogenology. 2005; 63;1366-1377.

11. Pereira MHC, Wiltbank MC, Vasconcelos JLM.:Expression of Estrous improves fertility and decreases pregnancy losses in lactating dairy cows that receive artificial insemination or embryo transfer. $J$ Dairy Sci. 2016: 99: 2237-2247. 
12. Palmer MA, Olmos G, Bóyle LA, et al. : Estrous detection and Estrous characteristics in housed and pastured Holstein-Friesian cows. Theriogenology. 2010: 74:255-264

13. Nogueira E, Cardoso GS, Junior HRM, et al. : Effect of breed and corpus luteum on pregnancy rate of bovine embryo recipient. $R$. Bras. Zootec. 2012: 41 (9); 1-10.

14. Du Ponte MW: The basics of Heat (estrus) detection in cattle. UH-CTAHR. LM-15. 2007; 1-3.

15. Roelofs, van Erp-van der Kooij E. Estrus detection tools in dairy cattle. Anim Reprod. 2015: 12: 3: 498-504.

16. Caccia M, Bó GA: Follicle wave emergence following treatment of CIDR-B implanted beef cows with estradiol benzoate and progesterone. Theriogenology. 1998; 341. [Abstract].

17. Baruselli SP, Ferreira RM, Filho MF, et al.: Bóvine embryo transfer recipient synchronisation and management in tropical enviroments. Reprod Fertil Dev. 2010; 22:67-74.

18. Reames PS, Hatler TB, Hayes SH, et al:: Differential regulation of estrous behavior and luteinizing hormone secretion by estradiol-17 $\beta$ in ovariectomized dairy cows. Theriogenology. 2011; 75:233-240.

19. Dahlen CR, Marquezini GHI, Larson JE, et al.: Fixedtime artificial insemination in replacement beef heifers after estrous synchronization with human chorionic gonadotrophins or gonadotropin-releasing hormone. $J$. Anim. Sci. 2012; 89:2750-2758.

20. Bó GA, Cedeno: A.Expression of estrous as a relevant factor in fixed-time embryo transfer programs using estradiol/progesterone-based protocols in cattle. Proceedings of the 32nd Annual Meeting of the Brazilian Embryo Technology Society (SBTE): Florianopólis, SC, Brazil, August 16th to 18 $8^{\text {th }} .2018$.

21. Berg DK, Van Leeuwen S, Beumont M, et al. : Embryo loss in cattle between days 7 and 16 of pregnancy. Theriogenology. 2010; 73(2):250-260.

22. Dunne LD, Diskin MG, Sreenan JM: Embryo and foetal loss in beef heifers between day 14 of gestation and full term. Anim Reprod Sci. 2000; 58:39-44.
23. Atkins JA, Smith MF, MacNeil MD, et al.: Pregnancy establishment and maintenance in cattle. J Anim Sci. 2013; 91:722-733.

24. Jinks EM, Smith MF, Atkins JA, et al.: Preovulatory estradiol and the establishment and maintenance of pregnancy in suckled beef cows. J Anim Sci. 2013: 91:1176-1185.

25. Miller B, Moore GNW, et al.: Early pregnancy in the ewe: effects of oestradiol and progesterone on uterine metaBólism and on embryo survival. Aust. J. Biol. Sci. 1977; 30:279-288.

26. Madsen CA, Perry GA, Mogck CL, et al: : Effects of preovulatory estradiol on embryo survival and pregnancy establishment in beef cows. Anim Reprod Sci. 2015; 158:96-103.

27. Romano EJ, Larson JE: Accuracy of pregnancy specific protein-B test for early pregnancy diagnosis in dairy cattle. Theriogenology. 2010; 74:932-939.

28. SemamBó DKN, Eckersall PD, Sasser RG, et al.: Pregnancy-spesific protein $B$ and progesterone in monitoring viability of the embryo in early pregnancy in the cow after experimental infection with Actinomyces pyogenes. Theriogenology. 1992; 37:741748.

29. Davoodi S, Cooke RF, Fernandes AC, et al.: Expression of estrous modifies the gene expression profile in reproductive tissues on day 19 of gestation in beef cows. Theriogenology. 2016; 85:645-655.

30. Grygar I Kudla'c E, Dolezel R: Volume of luteal tissue and concentration of serum progesterone in cow bearing homogenous corpus luteum or corpus luteum with cavity. Anim Repro Sci. 1997; 49: 77-82.

31. Cavalieri J: Absence of a corpus luteum and relatively lesser concentrations of progesterone during the period of pre-ovulatory follicle emergence results in lesser pregnancy rates in Bos indicus cattle. Theriogenology.2019; 204:39-49.

32. Lonergan AP, Forde NB, Spencer TC: Role of progesterone in embryo development in cattle. Reprod Fertil Dev. 2016; 28: 66-74. 